\title{
Cumulative Discounted Expressions of Sire Genotypes for the Complex Vertebral Malformation and $\beta$-Casein Loci in Commercial Dairy Herds
}

\author{
J. F. Kearney, ${ }^{1}$ P. R. Amer, ${ }^{2}$ and B. Villanueva ${ }^{1}$ \\ ${ }^{1}$ Sustainable Livestock Systems Group, Scottish Agricultural College, Bush Estate, Penicuik, Midlothian, \\ EH26 OPH, United Kingdom \\ ${ }^{2}$ Abacus Biotech Limited, P. O. Box 5585, Dunedin, New Zealand
}

\section{ABSTRACT}

Based on discounted gene-flow principles, a set of recursive equations was developed to quantify the value of using sires with a specific genotype for an identified gene in a commercial dairy herd. Two examples were used to demonstrate the usefulness of the method. The first example deals with the implications of using sires that are known carriers of the lethal recessive genetic defect, complex vertebral malformation (CVM). The second example examines the value of using sires homozygous for the $A 2$ allele of $\beta$-casein. Results are presented in terms of cumulative discounted expressions. These are then multiplied by the economic values of specific genotypes to determine the cost or benefit of using these sires. In general, the degree of mortality and the required price reduction for carrier sires increased as the proportion of carrier sires used, the duration of sire use, and the initial frequency in the cow herd increased. A semen discount of $£ 3.10$ per CVM straw used would be required to offset the expected mortality when $20 \%$ of CVM carrier sires are used for 3 yr when 5\% of cows are carriers. The cumulative discounted expressions' of using sires homozygous for the $A 2$ allele of $\beta$-casein also increased when the proportion and duration of carrier sire use and the initial frequency of the $A 2$ allele increased. Assuming an $A 2 A 2$ cow is worth $£ 160$ more than a non-A2A2 cow, the expected benefit of using A2A2 sires in a 100-cow herd for 5 yr would be $£ 57,120$ for a 20-yr planning horizon. The results of this study demonstrate how the starting gene frequency in the herd, and the proportion and duration of use of sires of particular genotypes are critical to the economic implications of using single genes in commercial dairy farms. (Key words: gene-flow, genotype, cumulative discounted expression, commercial dairy herd)

Abbreviation key: $\mathbf{C D E}=$ cumulative discounted expressions, $\mathbf{C V M}$ = complex vertebral malformation .

Received June 10, 2005.

Accepted August 2, 2005.

Corresponding author: J. F. Kearney; e-mail: fkearney@icbf.com.

\section{INTRODUCTION}

Dairy cattle genetics is a dynamic industry with breeding companies and breeders constantly facing new challenges. The emergence of molecular genetics has presented the industry with new technologies that can be used in conjunction with traditional selection methods to enhance genetic progress. For example, DNA tests for the detection of genetic defects are widely used (Dekkers, 2004). More recently, DNA-based tests have been developed whereby an animal with a favorable genotype for a specific trait (e.g., feed intake, marbling, reproduction, milk production) can be selected to increase the rate of genetic gain for that trait (Dekkers, 2004).

Genetic defects are often uncovered retrospectively. For instance, complex vertebral malformation (CVM), a recessive defect resulting in early abortion or stillbirths, was discovered only recently (Agerholm et al., 2001) but its origin can be traced back to a bull used several decades ago. Breeding companies often continue to market sires with a single copy of a deleterious allele, especially those of high genetic merit. Currently, 16 of the Top 100 Holstein sires for production in the United Kingdom are CVM carriers (Holstein UK, 2004). Often breeders continue to use these sires, perhaps without due consideration of the effects resulting in the herd. To make fully informed decisions, some questions should first be answered. For example, what are the costs and benefits of using carrier sires in a herd over time? Furthermore, should the cost per unit semen of a carrier sire be less than that of a sire with no copies of the defective allele but with equal genetic merit for a particular breeding objective?

The assessment of the costs and benefits of using commercially available DNA-based tests to aid selection for traits of economic importance is imperative before employing them as a tool in selection. One such test is for the $A 2$ variant of $\beta$-casein. Currently, a premium is being paid for homozygous A2A2 milk in New Zealand and Australia.

Discounted gene-flow techniques are useful for assessing the benefits of using genotypic information 
when making breeding decisions (e.g., Amer, 1999; Wood et al., 2004). These techniques account for the fact that benefits or costs realized from genetic expressions in future years have lower effective value than those incurred immediately.

The objective of this study was to evaluate the use of sires carrying specific alleles of interest in commercial dairy herds by applying discounted gene-flow techniques. Two applications of using genotypic information at the commercial herd level were used to illustrate the method.

\section{MATERIALS AND METHODS}

In a dairy herd, the genes of a particular sire are expressed not only in its daughters but in all its descendants. The cumulative expressions using a sire of a particular genotype in the herd depend on a number of factors including the age distribution of cows in the herd, the frequencies of cow genotypes, the number of years a sire is used, and the planning horizon.

Let $p_{j, t}$ be the proportion of sires of genotype $j$ at year $t$. These proportions were specified in advance for each of the genotypes and for each of the years $t=0$ to $t=$ $h-1$, in which $h$ is the planning horizon beyond which influences of the allele of interest are ignored. Moreover, let $s_{l}$ be the proportion of breeding cows of age $l$, and $w_{k, l, t}$ the proportion of cows of genotype $k$, age $l$ at time $t$. For this study, the minimum breeding age was 1 and the maximum breeding age was 7 (i.e., $l=1$ to 7 ). Therefore, the proportion of cows of genotype $k$ mated at time $t\left(c_{k, t}\right)$ in the herd can be computed as:

$$
c_{k, t}=\sum_{l=1}^{7} s_{l} w_{k, l, t} .
$$

The proportion of offspring of genotype $i$ at time of birth $t\left(o_{i, t}\right)$, under the assumption of random mating and no differential effect of the alleles on fitness, can be calculated from:

$$
o_{i, t}=\sum_{j=1}^{n} \sum_{k=1}^{n} P\left(o_{i, t} \mid S_{j}, D_{k}\right) p_{j, t-1} c_{k, t-1}
$$

where $n$ is the number of genotypes for the gene of interest and $P\left(o_{i, t} \mid S_{j}, D_{k}\right)$ is the probability of an offspring of genotype $i$ at time $t$, given a sire of genotype $S_{j}$ and a dam of genotype $D_{k}$, and can be calculated from simple Mendelian rules. For example, for a gene with 2 alleles $\mathrm{A}$ and a, $P\left(o_{i}=\mathrm{AA} \mid S_{j}=\mathrm{AA}, D_{k}=\mathrm{AA}\right)=$ 1 , and $P\left(o_{i}=\mathrm{Aa} \mid S_{j}=\mathrm{Aa}, D_{k}=\mathrm{Aa}\right)=0.5$, and so on. Thus, the probability of an offspring at time $t$ depends on the Mendelian inheritance rules for offspring genotype probabilities given parent genotypes, and the prob- abilities of genotype combinations for parents at time $t-1$.

From equation [2], it is clear that the herd genotypes $\left(c_{i, t}\right)$ and offspring genotypes $\left(o_{i, t}\right)$ are interdependent and must be computed recursively. At $t=0$, the proportion of cows of each genotype and age $\left(w_{k, l, 0}\right)$ was specified assuming Hardy-Weinberg equilibrium in the herd. The initial distribution of genotypes was assumed the same across age groups. The proportions of cows $1 \mathrm{yr}$ old $\left(s_{1}\right)$ and older in year $t=1\left(s_{2}\right.$ to 7$)$ are computed from the proportions in year $t=0$ lagged by $1 \mathrm{yr}$ of age. Breeding cow genotypes in year $t$ are computed using equation 1. From this, and the proportion of bulls used at time $t$, new offspring genotype proportions can be computed for year $t+1$ using equation 2 .

In this study, we were interested in the consequences (in terms of costs and benefits) of increasing the proportion of homozygous recessive animals as a result of using sires of a particular genotype (see case studies below). The cases considered involved biallelic loci (alleles A and a). The cumulative expressions of the sires' genes over the planning horizon need to be discounted back to the time when the sire was first used to account for the delays in the expression of genes.

Let $\mathbf{q}$ be a discounting vector with elements

$$
q_{i}=\left(\frac{1}{1+r}\right)^{i-1}
$$

where $i=1$ to $h$ and $r$ is the discount rate. Four different discount rates were considered.

The cumulative discounted expressions (CDE) for the expression of genotype $i$ for calves at birth (required for case study I) were calculated by multiplying the proportion of homozygous animals for the recessive allele in year $t$, by the corresponding element of $\mathbf{q}$ and summed over all years:

$$
\mathrm{CDE}_{i}=\sum_{t=1}^{h} o_{i, t} q_{t} .
$$

The CDE for the expression of genotype $k$ for cows in any lactation (required for case study II) was calculated as:

$$
\mathrm{CDE}_{k}=\sum_{t=1}^{h} c_{k, t} q_{t} .
$$

The CDE were then multiplied by the economic values of specific genotypes of interest to determine the value of using particular sire genotypes. 


\section{Effect on Semen Price}

Given the risks associated with using carrier sires it may be appropriate to pay less for semen from these sires. Likewise, the benefit accruing from using $A 2 A 2$ sires could result in a premium being paid for such semen. A reduction or premium (£) per unit semen was calculated as:

\section{Semen Reduction/Premium $=$}

Cost / Benefit of the gene $\times C D E$

$\overline{\text { Units of semen used } \times \text { Services per conception } \times \text { Matings }}$

where Matings is the effective number of matings of sires of the genotype of interest assumed in the computation of the CDE. The value of the variable Matings is computed as the sum (over years) of proportions of sires with the specific genotype of interest used in each year of the planning horizon. The cost of using CVM carrier sires was assumed to be the cost of a dead calf and the benefit of using A2A2 sires was the value of an $A 2 A 2$ cow vs. a non-A2A2 cow. The value assumed for the number of services per conception was 1.7, which corresponds to the mean value found in UK cows (Wall et al., 2003).

\section{Case Study I}

This case study examines the costs associated with using a sire that is a carrier for a lethal recessive genetic defect such as CVM. The following parameters would influence the impact of using a CVM carrier sire on a herd: 1) the frequency of carrier cows in the herd; 2) the proportion of carrier sires used each year; 3) the number of years that carrier sires are used, and 4) the cost of each recessive case. Due to the nature of CVM, it was assumed that all recessive animals $(a a)$ die. Because of this, it is necessary to adjust the proportions of the homozygous normal and heterozygous animals to ensure that the genotype proportions sum to 1 . This was done by dividing the proportion of homozygous normal or heterozygous by 1 minus the proportion of recessives. Carrier sires were assumed to be used for either 1 or $3 \mathrm{yr}$ and different proportions (20,50, and 100\%) of carrier sires were considered. Three years was considered the maximum number of years to avoid the risk of excessive mortality as the frequency of CVM increased. The initial frequency of CVM carrier cows in the herd was $0,0.05,0.1$, or 0.2 .

Cost of a recessive CVM case. There will be several costs incurred due to a cow carrying a calf homozygous for the deleterious allele such as veterinary costs, culling and replacement costs, and the calf loss. Nielsen et al. (2003) found that not all cows retain a CVM fetus for the entire gestation period. They calculated that $29 \%$ of carrier cows would abort before $d 100,45 \%$ before d 150 , and $77 \%$ before $d 260$. It is likely that the cows aborting after d 150 would be culled, whereas those that abort earlier would be retained in the herd. Based on this, we assumed for this study that $50 \%$ of carrier cows are culled, and $50 \%$ are retained. The value of an involuntarily culled cow depends on the age of the animal, and the current market value of a culled cow. The average cull value for cows is approximately $£ 300$ (Stott et al., 2005). Allowing a cost of $£ 85$ for veterinary expenses and labor, $£ 200$ for mean calf value, and $£ 600$ for replacement costs (excluding the value of the culled cow), the approximate cost of a case of CVM resulting in a cow being involuntarily culled is $£ 585$. For a cow with milk yield averaging $6000 \mathrm{~L} / \mathrm{yr}$, the cost of a delay in conception when conception occurs after $150 \mathrm{~d}$ is estimated at $£ 253$ (Esslemont et al., 2000). Assuming that $50 \%$ of cows are culled and $50 \%$ survive, the average cost of a CVM case would be $£ 419$ [i.e., ( $253+$ $585) / 2]$.

\section{Case Study II}

The second case study investigated the value of using sires genotyped for the $A 2$ variant of the $\beta$-casein gene. Premiums are paid for milk that is homozygous for the A2 allele; therefore, a commercial herd manager would be interested in the returns from using $A 2 A 2$ sires, and in the length of time taken to obtain a homozygous A2A2 herd. Only milk from cows with 2 copies of the A2 allele is desired and therefore only A2A2 animals are of interest. The initial proportion of A2A2 cows in the herd was $0,0.0225,0.25$, and 0.7225 , which, assuming Hardy-Weinberg equilibrium, corresponds to an initial allele frequency $\left(f_{A 2}\right)$ equal to $0,0.15,0.5$, and 0.85 . These values were chosen arbitrarily to represent zero, low, intermediate, and high initial allele frequencies in the population, respectively. The CDE of using either A2A2 or A1A2 sires over the planning horizon were obtained as described above. The CDE were then multiplied by the economic value of $A 2$ milk (see below) to calculate the potential value from using sires carrying the $A 2$ allele.

Value of A2A2 milk. Currently, New Zealand and Australia are the only countries paying a premium for A2A2 milk. In New Zealand, a small group of suppliers receives a premium equivalent to $£ 0.04 / \mathrm{L}$ for $A 2$ milk (J. Allison, Abacus Biotech, New Zealand, personal communication). For a cow producing $4000 \mathrm{~L}$ of milk per year, the value of an A2A2 genotype with such a premium would be $£ 160$ more per lactation than a nonA2A2 cow. It is assumed that A2A2 cows can be milked separately from other cows, because mixing of their 
Table 1. Number of dead calves expected in a 100-cow herd when varying proportions of complex vertebral malformation carrier sires (CS, in \%) are used for 1 or $3 \mathrm{yr}$ with different initial carrier cow frequencies.

\begin{tabular}{|c|c|c|c|c|c|c|}
\hline \multirow{2}{*}{$\begin{array}{l}\text { Carrier cow } \\
\text { frequency }\end{array}$} & \multicolumn{3}{|c|}{ Carrier sires used for $1 \mathrm{yr}$} & \multicolumn{3}{|c|}{ Carrier sires used for $3 \mathrm{yr}$} \\
\hline & $\mathrm{CS}=20$ & $\mathrm{CS}=50$ & $\mathrm{CS}=100$ & $\mathrm{CS}=20$ & $\mathrm{CS}=50$ & $\mathrm{CS}=100$ \\
\hline 0 & 0 & 0 & 0 & 1 & 1 & 4 \\
\hline 0.05 & 1 & 1 & 2 & 3 & 4 & 9 \\
\hline 0.10 & 1 & 2 & 3 & 3 & 6 & 12 \\
\hline 0.20 & 1 & 3 & 5 & 3 & 9 & 18 \\
\hline
\end{tabular}

milk with that of $A 1$ carrier cows eliminates any commercial premium.

\section{RESULTS}

For both case studies, we were interested in the homozygous ( $a$ a or A2A2) animals produced through use of sires of a particular genotype over a particular planning horizon. The planning horizon is the number of years a particular sire genotype is used plus the number of years until the genetic influence of descendents becomes negligible. For example, in case study I, carrier sires were used for a maximum of $3 \mathrm{yr}$; therefore, the results refer to a planning horizon of $11 \mathrm{yr}$ because all effects of using these sires were minimal after this number of years.

\section{Case Study I}

The number of dead calves ( $a a$ ) expected for the situations investigated (rounded to the next highest integer) is shown in Table 1. No dead calves are expected when there are no carrier cows in the herd and carrier sires are used for $1 \mathrm{yr}$ only. When carrier sires are used for $3 \mathrm{yr}$ and there are no carriers in the herd initially, dead calves begin to appear as heterozygous cows are mated to carrier sires in year 3 . As expected, the number of dead calves increased with the proportion of carrier sires used and with increasing carrier cow frequency.

The CDE resulting from using varying proportions of carrier sires in a herd with different carrier frequencies are shown in Table 2. For this case study, the CDE represent the discounted equivalent number of dead calves, which increases with the proportion of carrier sires used. When carrier sires are used for $1 \mathrm{yr}$ only, the CDE doubles with a doubling of the carrier frequency in the herd. A linear relationship between the number of $\mathrm{CDE}$ and the proportion of carrier sires used also exists when carrier sires are used for $3 \mathrm{yr}$. Higher discount rates lead to decreased expressions. Proportionally, this reduction was highest when the carrier cow frequency was lowest. For example, when the carrier frequency was zero, the reduction in expressions is $33 \%$ between

Table 2. Cumulative discounted expressions (CDE) as result of using different proportions of complex vertebral malformation carrier sires (CS, in \%) over 1 or $3 \mathrm{yr}$ in 100-cow herds with different carrier cow frequencies for different discount rates, and a planning horizon of $20 \mathrm{yr}$.

\begin{tabular}{|c|c|c|c|c|c|c|c|}
\hline \multirow{2}{*}{$\begin{array}{l}\text { Carrier cow } \\
\text { frequency }\end{array}$} & \multirow{2}{*}{$\begin{array}{l}\text { Discount } \\
\text { rate }\end{array}$} & \multicolumn{3}{|c|}{ Carrier sires used for $1 \mathrm{yr}$} & \multicolumn{3}{|c|}{ Carrier sires used for $3 \mathrm{yr}$} \\
\hline & & $\mathrm{CS}=20$ & $\mathrm{CS}=50$ & $\mathrm{CS}=100$ & $\mathrm{CS}=20$ & $\mathrm{CS}=50$ & $\mathrm{CS}=100$ \\
\hline \multirow[t]{4}{*}{0} & 0.05 & 0 & 0 & 0 & 0.13 & 0.81 & 3.24 \\
\hline & 0.07 & 0 & 0 & 0 & 0.12 & 0.77 & 3.06 \\
\hline & 0.10 & 0 & 0 & 0 & 0.11 & 0.70 & 2.82 \\
\hline & 0.20 & 0 & 0 & 0 & 0.09 & 0.54 & 2.17 \\
\hline \multirow[t]{4}{*}{0.05} & 0.05 & 0.24 & 0.60 & 1.19 & 0.77 & 2.4 & 6.36 \\
\hline & 0.07 & 0.23 & 0.58 & 1.17 & 0.74 & 2.30 & 6.07 \\
\hline & 0.10 & 0.23 & 0.57 & 1.14 & 0.70 & 2.16 & 5.68 \\
\hline & 0.20 & 0.21 & 0.52 & 1.04 & 0.59 & 1.78 & 4.60 \\
\hline \multirow[t]{4}{*}{0.10} & 0.05 & 0.48 & 1.19 & 2.38 & 1.41 & 3.98 & 9.48 \\
\hline & 0.07 & 0.47 & 1.17 & 2.34 & 1.36 & 3.83 & 9.08 \\
\hline & 0.10 & 0.46 & 1.14 & 2.27 & 1.29 & 3.61 & 8.54 \\
\hline & 0.20 & 0.42 & 1.04 & 2.08 & 1.09 & 3.02 & 7.06 \\
\hline \multirow[t]{4}{*}{0.20} & 0.05 & 0.95 & 2.38 & 4.76 & 2.7 & 7.16 & 15.73 \\
\hline & 0.07 & 0.94 & 2.34 & 4.67 & 2.60 & 6.89 & 15.12 \\
\hline & 0.10 & 0.91 & 2.27 & 4.55 & 2.47 & 6.52 & 14.27 \\
\hline & 0.20 & 0.83 & 2.08 & 4.17 & 2.09 & 5.50 & 11.95 \\
\hline
\end{tabular}


Table 3. Effect of the proportion of carrier sires used (CS, in \%), number of years in which carrier sires are used, and initial carrier cow frequency on the semen reduction required (£ per complex vertebral malformation straw used) when the cost of a dead calf is $£ 419$ and the discount rate is 0.07 .

\begin{tabular}{lccccccc}
\hline \multirow{2}{*}{$\begin{array}{l}\text { Carrier cow } \\
\text { frequency }\end{array}$} & \multicolumn{3}{c}{ Carrier sires used for $1 \mathrm{yr}$} & & \multicolumn{3}{c}{ Carrier sires used for 3 yr } \\
\cline { 2 - 3 } & $\mathrm{CS}=20$ & $\mathrm{CS}=50$ & $\mathrm{CS}=100$ & & $\mathrm{CS}=20$ & CS=50 & CS=100 \\
\hline 0 & 0 & 0 & 0 & & 0.5 & 1.3 & 2.5 \\
0.05 & 2.8 & 2.9 & 2.9 & & 3.1 & 3.8 & 5.0 \\
0.10 & 5.8 & 5.8 & 5.8 & & 5.6 & 6.3 & 7.5 \\
0.20 & 11.6 & 11.6 & 11.6 & & 10.7 & 11.4 & 12.5 \\
\hline
\end{tabular}

a discount rate of 5 and $20 \%$, but when the frequency in the herd is 0.2 , the reduction is $24 \%$.

A reduction in price for a unit of carrier semen used was calculated to determine how much less should be paid for this semen vs. semen from a non-CVM carrier sire of equal genetic merit (Table 3 ). For a given carrier cow frequency, there is practically no difference in the reduction in price required for different proportions of carrier sires used for only $1 \mathrm{yr}$. Similar to the pattern observed for the number of expressions, the reduction required doubles when cow herd frequency doubles. The reduction in price required increases when carrier sires are used for a period of $3 \mathrm{yr}$ because both the number of carrier sires used increases and the frequency of carrier cows in the herd increases. In proportion, the reduction in price when using more carrier sires is greatest at lower cow herd frequencies. A $64 \%$ greater reduction would be required to break even when using all carrier sires when the cow frequency is $0.05 \mathrm{com}$ pared with just $16 \%$ when the cow frequency is 0.2 .

Table 4. Cumulative discounted expressions (CDE) as a result of using homozygous sires for the A2 variant of the $\beta$-casein gene (A2A2) for a different number of years in a 100-cow herd with different initial cow frequencies and a planning horizon of $20 \mathrm{yr}$.

\begin{tabular}{lllll}
\hline \multirow{2}{*}{$\begin{array}{l}\text { Initial cow } \\
\text { frequency }\end{array}$} & $\begin{array}{l}\text { Discount } \\
\text { rate }\end{array}$ & \multicolumn{3}{c}{ No. of years A2A2 sires used } \\
\cline { 3 - 5 } 0 & 0.05 & 0 & 5 & 10 \\
\hline 0.07 & 0 & 323 & 528 \\
& 0.10 & 0 & 277 & 495 \\
& 0.20 & 0 & 209 & 451 \\
0.0225 & 0.05 & 13 & 394 & 610 \\
& 0.07 & 12 & 369 & 570 \\
& 0.10 & 11 & 336 & 520 \\
& 0.20 & 8 & 254 & 391 \\
0.25 & 0.05 & 42 & 557 & 800 \\
& 0.07 & 39 & 522 & 750 \\
& 0.10 & 36 & 475 & 682 \\
& 0.20 & 27 & 357 & 513 \\
0.7225 & 0.05 & 71 & 720 & 991 \\
& 0.07 & 67 & 674 & 929 \\
& 0.10 & 60 & 614 & 845 \\
& 0.20 & 45 & 461 & 633 \\
\hline
\end{tabular}

\section{Case Study II}

The CDE from using sires homozygous for the A2 variant of $\beta$-casein are shown in Table 4 . As expected, the number of CDE increase when the number of years of using homozygous recessive (A2A2) sires and the initial frequency of the herd increases. When the initial frequency of $A 2 A 2$ cows is zero, there is no benefit from using A2A2 sires for just $1 \mathrm{yr}$. The increase in CDE when using A2A2 sires for 10 instead of for $5 \mathrm{yr}$ is greater at lower cow frequencies. When the initial frequency of $A 2 A 2$ cows in the herd is zero, there is a $63 \%$ increase in CDE when $A 2 A 2$ sires are used for 10 vs. $5 \mathrm{yr}$. The increase is 54,43 , and $37 \%$ for initial cow frequencies of $0.0225,0.25$, and 0.7225 , respectively. As in the previous case study, the number of CDE decreases as the discount rate increases.

The premium per unit semen was calculated when A2A2 sires were used for 1,5 , or $10 \mathrm{yr}$, and is shown in Table 5. The amount of the premium could also be thought of as the reduction that should be paid for nonA2A2 semen. Not surprisingly, the value of $A 2 A 2$ semen is considerable when used for 5 or $10 \mathrm{yr}$ compared with just using it for $1 \mathrm{yr}$.

Figure 1 compares the CDE over the planning horizon when all sires used are either A2A2 or A1A2 for 2 initial starting frequencies of $A 2 A 2$ cows in the herd. When only A2A2 sires are used and the initial $A 2 A 2$ frequency in the herd is $0.7225\left(f_{A 2}=0.85\right.$, where $f_{A 2}$ is the frequency of the $A 2$ allele), there is a linear increase in $\mathrm{CDE}$ over the planning horizon. A similar pattern

Table 5. Effect of the number of years semen from homozygous sires for the A2 variant of the $\beta$-casein gene (A2A2) is used, and initial carrier cow frequency on the semen premium (£ per A2A2 straw used) when the value of an $A 2 A 2$ cow is $£ 160$ more per lactation than a non- $A 2 A 2$ cow, and the discount rate is 0.2 .

\begin{tabular}{llll}
\hline \multirow{2}{*}{$\begin{array}{l}\text { Carrier cow } \\
\text { frequency }\end{array}$} & \multicolumn{3}{c}{ No. of years A2A2 sires used } \\
\cline { 2 - 4 } & 1 & 5 & 10 \\
\hline 0 & 0 & 3.93 & 3.20 \\
0.0225 & 0.75 & 4.78 & 3.68 \\
0.25 & 2.50 & 6.75 & 4.82 \\
0.7225 & 4.25 & 8.67 & 5.96 \\
\hline
\end{tabular}




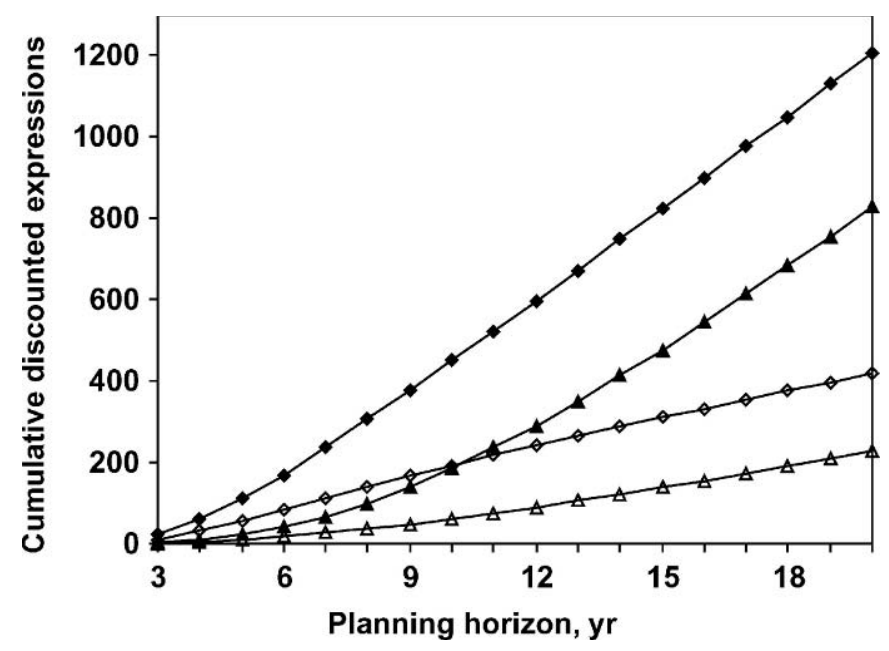

Figure 1. Number of cumulative discounted expressions over the planning horizon when either all $A 2 A 2(\diamond, \mathbf{\Delta})$ or all A1A2 $(\diamond, \triangle)$ sires are used and the initial frequency of the $A 2$ allele in the herd is $0.15(\boldsymbol{\Delta}, \triangle)$ or $0.85(\diamond, \diamond)$.

emerges when only A1A2 sires are used but the number of CDE is 3 times less than when $A 2 A 2$ sires are used. When the initial frequency of $A 2 A 2$ cows in the herd is $0.0225\left(f_{A 2}=0.15\right)$, the rate of increase in the CDE is slow until around yr 12, after which the CDE increase linearly. After $20 \mathrm{yr}$, the CDE is 828 compared with 1209 when the initial frequency is 0.7225 .

The evolution of the allelic frequency for $A 2$ over the planning horizon is shown in Figure 2. When the initial frequency in the herd is high and A2A2 sires are used continuously, the frequency in the herd increases to-

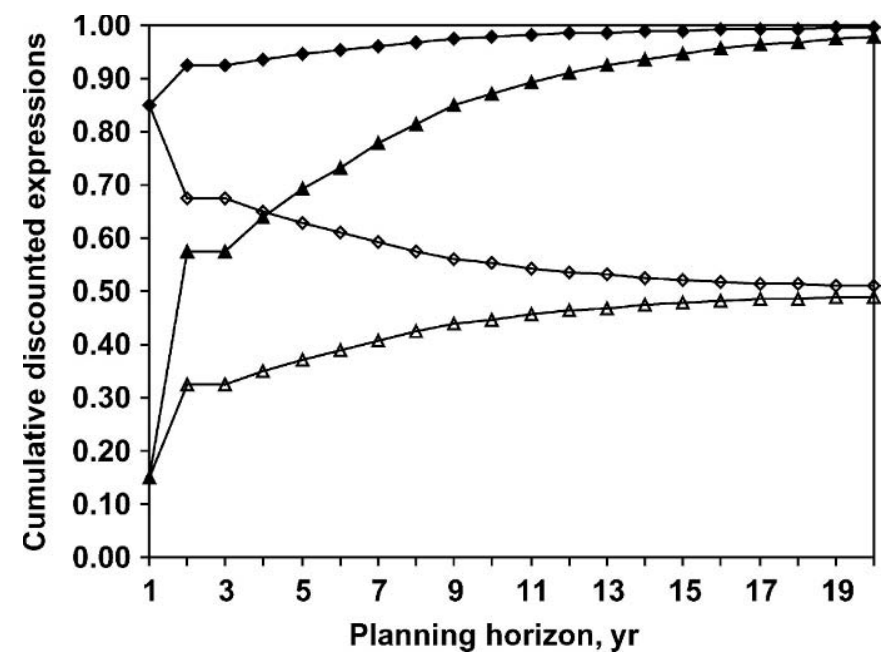

Figure 2. Evolution of the $A 2$ allele frequency in the herd when either all $A 2 A 2(\diamond, \mathbf{\Delta})$ or all $A 1 A 2(\diamond, \triangle)$ sires are used and the initial frequency of the $A 2$ allele in the herd is $0.15(\Delta, \triangle)$ or 0.85 $(\diamond, \diamond)$. ward 1 . The greatest increases occur in the earlier years when there is more scope for selection of A2A2 cows. However, when A1A2 sires are used, the frequency of the $A 2$ allele decreases toward 0.5 . The greatest decrease occurs the year after the A1A2 sires begin to be used. When only A2A2 sires are used and the initial frequency is low, the greatest increase occurs in the first years, and then the frequency increases steadily toward 1. A frequency of 0.9 is reached after $12 \mathrm{yr}$. Using A1A2 sires increases the frequency of the gene to about 0.5 .

The value of using an $A 2 A 2$ sire can be calculated from the CDE and the economic value of $A 2 A 2$ milk. For example, the CDE of using an A2A2 sire for $5 \mathrm{yr}$ in a 100-cow herd, when $25 \%$ of the herd is A2A2 (approximate proportion of $A 2 A 2$ cows in New Zealand) at a discount rate of $20 \%$ is 357 (Table 4). Assuming that the value of milk from $A 2 A 2$ cows is $£ 160$ more than non- $A 2$ milk, and a planning horizon of $20 \mathrm{yr}$, the benefit of using A2A2 sires over non-A2A2 sires that are otherwise equal in merit, is $357 \times £ 160$, giving a economic return of $£ 57,120$.

\section{DISCUSSION}

This study demonstrates the complexity of the economic implications of using information for a single genetic locus with nonadditive economic effects when selecting bulls to use to mate cows in a commercial dairy herd. There is extensive literature dealing with the economic implications of selection decisions in relation to expression of differences in estimated breeding values (e.g., VanRaden, 2004; Miglior et al., 2005). These approaches involve tracing the multiple expressions of the sires' genes for a range of traits in their descendants at specific ages. For a single locus with nonadditive economic effects, the results here demonstrate that further account must be taken of the starting genotype frequencies in the herd, and the duration of use of bulls of specified genotypes.

Despite the existence of numerous genetic defects in dairy cattle, little research has been done on the effects of using a carrier sire of such defects in a cow herd. Superior sires that are carriers will often continue to be marketed. Advice on whether to use carrier sires may be conflicting and is further complicated by the opposing policies of breeding companies on the sale of semen from carrier sires. It is generally assumed that over time a genetic defect will be eliminated. However, if carriers of a specific genetic defect have high genetic merit for other economically important traits, then the value of using a carrier sire could increase dramatically. To date, very little literature exists on the possible links between the CVM status and performance in other eco- 
nomically important traits in dairy cattle (Nielsen et al., 2003; Hansen et al., 2004).

The ethical issues of using CVM carrier sires have not been considered here because they are difficult to quantify, but they are likely to be important to both farmers and consumers. Rather, we have looked at the economic implications of using sires that carry one copy of the allele responsible for CVM. The cumulative discounted expressions were calculated for situations where the proportion of carrier sires, the duration of carrier sire use, the initial frequency of carriers in the herd, and the discount rate varied. When the initial cow carrier frequency is zero, there is no loss accrued from using carrier sires for $1 \mathrm{yr}$ only. When carrier sires are used for $3 \mathrm{yr}$, the CDE are greater than 3 times the 1-yr values because the frequency of carrier cows will be increased as a result of using a carrier sire initially and also because a greater proportion of carrier sires are mated to carrier females in yr 2 and 3, resulting in more expressions. In terms of the actual number of dead calves, if the frequency of carrier cows in a herd were unknown, it appears that the best strategy would be to keep carrier use at or below $20 \%$. For the carrier cow frequencies investigated, there was no difference in the number of dead calves expected when $20 \%$ carrier sires are used. However, the number of dead calves increases with carrier cow frequency when 50 or $100 \%$ of carrier sires are used.

Using a carrier sire involves a certain amount of financial risk; therefore, a breeder should be able to purchase semen from a carrier sire for less than a noncarrier sire of equal genetic merit. In general, a greater reduction in the cost of CVM semen is required with increased carrier sire use and cow frequency. It is unlikely that the frequency of carrier cows in a herd is zero; therefore, it is evident from these results that many breeders will require a reduction in semen price before using carrier sires of a known genetic defect when compared with noncarrier sires of equal genetic merit.

Most studies investigating the benefit of using genes of known effect or markers linked to them in dairy breeding programs have focused on their use in nucleus breeding herds (Meuwissen and van Arendonk, 1992; Schrooten et al., 2005). However, DNA-based tests are now available to commercial breeders to allow them to select for a gene influencing a specific trait. Apart from parentage checking and genetic defect testing, DNA tests are available for genes affecting quantitative traits such as milk yield and composition ( $\beta$-lactoglobulin, $\beta$ - and $\kappa$-casein, DGAT1, bovine growth hormone receptor) and feed intake (leptin). Alleles of $\beta$-lactoglobulin were shown to increase cheese yield without affecting quality or taste, and the B allele of $\kappa$-casein has favorable effects on milking processing properties. Properties such as these are likely to realize a premium from milk processing companies, and therefore, increase the profitability of an enterprise. Recent studies have suggested a link between the $A 2$ variant of $\beta$ casein and favorable health benefits (e.g., Laugesen and Elliot, 2003; Tailford et al., 2003). If such a relationship exists, then it might be desirable for a producer to increase the frequency of $A 2$ cows in the herd as the value of milk from these animals may be significantly increased. Even with a high discount rate of $20 \%$ (i.e., in which more preference is given to earlier expressions), we have shown that there is considerable benefit from using $A 2 A 2$ sires to increase the frequency of $A 2 A 2$ cows when a premium is paid for milk from these cows. The higher the initial allele frequency, the greater the benefit, because it takes 6 to $7 \mathrm{yr}$ to build up the proportion of $A 2 A 2$ cows in the herd when the initial frequency is low. Continual use of $A 2 A 2$ sires will increase the proportion of $A 2 A 2$ cows in the herd but the time taken to have a pure $A 2 A 2$ herd will depend on the initial frequency in the cow herd. Even when the $A 2$ allele is at a low frequency (0.15), the use of $A 2 A 2$ sires for 1 yr can increase the proportion of A2A2 cows in the herd to $>50 \%$ after 3 yr. A more rapid but expensive method of increasing the proportion of A2A2 cows would necessitate genotyping all the cows in the herd. The genotypes could then be used in culling and selection decisions to maximize the proportion of $A 2 A 2$ replacements.

In these studies, we were only interested in one particular offspring genotype. The same approach can be used to determine the value of sires in a situation in which heterozygous descendants also contribute to the value of a sire. The CDE from this scenario would be greater than those obtained here because heterozygous (Aa) animals would contribute to the expressions in addition to the homozygous animals. The method can be used to calculate returns from 2 or more unlinked genes or QTL by calculating the returns independently for each gene and summing them. Similarly, the value of a pleiotropic QTL can be obtained by calculating the CDE for each trait separately, multiplying by the economic value of the QTL for each trait, and summing them.

Usually, indexes are available that quantify economic consequences of selecting bulls differing in genetic merit for polygenes. Depending on the base of expression of the index, a translation may be required to enable a meaningful tradeoff to be made between polygenic merit and the value of gene expression as calculated here.

\section{CONCLUSIONS}

This study quantifies the costs (in case study I) and benefits (in case study II) for 2 single genetic loci that 
have received some attention by dairy breeders in recent years. The results show how the starting gene frequency in the herd, and the proportion and duration of use of sires of particular genotypes are critical when evaluating the economic implications of the use of single genes in commercial dairy herds. In general, use of CVM carrier bulls should be restricted to less than $20 \%$ of matings unless the gene frequency in cows is known to be low. Where a homozygous genotype is commercially advantageous (e.g., A2A2 in New Zealand), the benefits of using homozygous sires will be greatest for those herds that already have a high frequency of the favorable allele. These examples demonstrate that sire selection decisions by commercial dairy farmers are substantially more complicated when information is available for specific genetic loci. Further research into decision support tools to facilitate efficient selection of sires by commercial farmers will be required as tests for specific genetic alleles become increasingly available.

\section{ACKNOWLEDGMENTS}

This work was funded by the Scottish Executive Environment \& Rural Affairs Department (SEERAD). J. F. Kearney would also like to acknowledge the National University of Ireland for studentship support.

\section{REFERENCES}

Agerholm, J. S., C. Bendixen, O. Andersen, and J. Arnbjerg. 2001. Complex vertebral malformation in Holstein calves. J. Vet. Diagn. Invest. 13:283-289.
Amer, P. R. 1999. Economic accounting of numbers of expressions and delays in sheep genetic improvement. N.Z. J. Agric. Res 42:325-336.

Dekkers, J. C. M. 2004. Commercial application of marker- and geneassisted selection in livestock: Strategies and lessons. J. Anim. Sci. 82(E. Suppl):E313-E328.

Esslemont, R. J., M. A. Kossaibati, and J. Allcock. 2000. Economics of fertility in dairy cows. M. G. Diskin, ed. Br. Soc. Anim. Sci. Occ. Publ. No. 26, Vol. 1:19-29.

Hansen, M., I. Misztal, M. S. Lund, J. Pedersen, and L. G. Christensen. 2004. Undesired phenotypic and genetic trend for stillbirth in Danish Holsteins. J. Dairy Sci. 87:1477-1486.

Holstein U.K. 2004. Subject: CVM. Online. Available at: http:// www.holstein-uk.org/. Accessed Dec. 1, 2004.

Laugesen, M., and R. Elliot. 2003. Ischaemic heart disease, type 1 diabetes, and cow milk A1 $\beta$-casein. N. Z. Med. J. 116:1168-1187.

Meuwissen, T. H. E., and J. A. M. van Arendonk. 1992. Potential improvements in rate of genetic gain from marker-assisted selection in dairy cattle breeding schemes. J. Dairy Sci. 75:1651-1659.

Miglior, F., B. L. Muir, and B. J. Van Doormaal. 2005. Selection indices in Holstein cattle of various countries. J. Dairy Sci. 88:1255-1263.

Nielsen, U. S., G. P. Aamand, O. Andersen, C. Bendixen, V. H. Nielsen, and J. S. Agerholm. 2003. Effects of complex vertebral malformation on fertility traits in Holstein cattle. Livest. Prod. Sci. 79:233-238.

Schrooten, C., H. Bovenhuis, J. A. M. van Arendonk, and P. Bijma. 2005. Genetic progress in multistage dairy cattle breeding schemes using genetic markers. J. Dairy Sci. 88:1569-1581.

Stott, A. W., M. P. Coffey, and S. Brotherstone. 2005. Including lameness and mastitis in a profit index for dairy cattle. Anim. Sci. 80:41-52.

Tailford, K. A., C. L. Berry, A. C. Thompson, and J. H. Campbell. 2003. A casein variant in cow's milk is atherogenic. Atherosclerosis $170: 13-19$.

VanRaden, P. M. 2004. Invited review: Selection on Net Merit to improve lifetime profit. J. Dairy Sci. 87:3125-3131.

Wall, E., S. Brotherstone, J. A. Woolliams, G. Banos, and M. P. Coffey. 2003. Genetic evaluation of fertility using direct and correlated traits. J. Dairy Sci. 86:4093-4102.

Wood, B. J., J. H. J. van der Werf, and P. F. Parnell. 2004. Valuing DNA marker tested bulls for commercial beef production. Aust. J. Agric. Res. 55:825-831. 